Portland State University

PDXScholar

10-26-1983

\title{
The Effects of a Combined Weight Training and Running Program on Body Composition in College
}

\section{Males}

Robert L. Hesslink Jr.

Portland State University

Follow this and additional works at: https://pdxscholar.library.pdx.edu/open_access_etds

Part of the Health and Physical Education Commons

Let us know how access to this document benefits you.

\section{Recommended Citation}

Hesslink, Robert L. Jr., "The Effects of a Combined Weight Training and Running Program on Body Composition in College Males" (1983). Dissertations and Theses. Paper 3319.

https://doi.org/10.15760/etd.3299

This Thesis is brought to you for free and open access. It has been accepted for inclusion in Dissertations and Theses by an authorized administrator of PDXScholar. Please contact us if we can make this document more accessible: pdxscholar@pdx.edu. 
AN ABSTRACT OF THE THESIS of Robert L. Hesslink, Jr. for the Master of Science in Teaching in Physical Education presented October 26, 1983.

Title: The Effects of a Combined Weight Training and Running Program on Body Composition in College Males.

APPG foYED /BY MEMBERS OF THE THESIS COMMITTEE:



Milzh Svoboda, Chairmañ

Jack Schendel

\section{Ien Kaufizan}

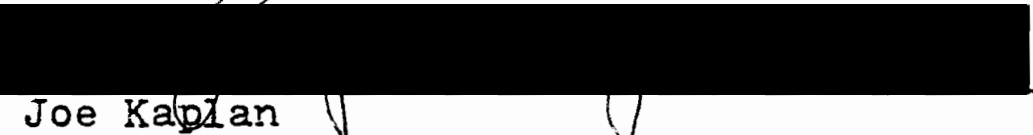

The present study attempted to investigate whether a combined weight and endurance training program can elicit more favorable changes in body composition than either method of training alone. Body composition parameters (absolute fat and fat-free weight) were evaluated using circumference measurements, skinfolds and hydrostatic weighing. Cardiorespiratory fitness was evaluated via a modified Harvard step-test. All tests were administered before and after 10 weeks of training. Exercises were performed 3 days/week for 40 minutes/day. Male volunteers $(n=21)$ were randomly assigned to one of three treatment groups (weight training only, endurance running only, combined weight training and endurance running). Weight 
training (Group I) was designed to elicit muscle hypertrophy and involved 5 sets of $8-10$ repetitions/set. Intensity was set at $80 \%$ of one repetition maximum for each lift. Subjects performed the parallel squat, bench press and dead-lift exercises. Endurance running (Group II) was designed to elicit cardiorespiratory improvement. Intensity was maintained at $60 \%$ of each subject's heart rate range. Subjects in the combined group (Group III) used the same weight training exercises as Group I except they performed 3 sets of $8-10$ repetitions/set in twenty minutes followed by twenty minutes of endurance running. Control subjects $(n=4)$ were selected from original candidates who could not meet the time requirements of the study $(8: 30$ a.m. $-10: 00$ a.m.,MWF $)$ and from physical education classes with low levels of activity (i.e. archery, bowling, golf). These subjects were instructed to remain sedentary during the 10 -weeks of the study. Differences among the groups on post-test scores were evaluated via analysis of covariance, using pre-test scores to reduce within group (error) variance. Tukey's HSD procedure was selected to evaluate further group differences in pairs when a significant F-ratio was obtained. Using the method of hydrostatic weighing, a significant F-ratio was found when analyzing post-test measures of fat-free weight $(F=5.3, p<.02)$. However, Tukey's procedure showed that the on?y significant 
pairwise comparison was the weight training group vs. the endurance group ( $p<.05 .68 .1 \mathrm{~kg}$ vs. $62.8 \mathrm{~kg}$, respectively). F-ratios for absolute fat $(F=.02, p<.89)$ and total body weight $(F=1.8, p<.22)$ were not significantly different. There were no significant post-test differences for absolute fat $(F=.46, p<.71)$, fat-free weight $(F=.48$, $\mathrm{p}<.70)$ or circumference sum $(\mathrm{F}=.48, \mathrm{p}<.70)$ using circumference measurements. Skinfold techniques did not show significant difference for absolute fat $(F=.63$, $p<.62)$, fat-free weight $(F=1.5, p<.28)$ or skinfold sum $(F=.48, p<.70)$. Analysis of the step-test data resulted in a significant F-ratio for heart rate response on the post-test $(F=6.5, p<.01)$. Using Tukey's procedure, the mean heart rate of the combined group (104 bpm) was significantly lower than that of the control group, $(139.3 \mathrm{bpm})$ and that of the weight training group $(138.8 \mathrm{bpm})$. In summary, the present study suggests that a combined weight and endurance training program does not elicit more favorable changes in body composition than either method of training alone. The combined program did, however, provide minimal improvement in cardiorespiratory fitness suggesting that twenty minutes of running can elicity measureable improvement. 
THE EFFECTS OF A COMBINED WEIGHT TRAINING AND RUNNING PROGRAM ON BODY COMPOSITION

IN COLLEGE MALES

by

ROBERT I. HESSIINK, JR.

A thesis submitted in partial fulfillment of the requirements for the degree of

\author{
MASTER OF SCIENCE \\ in \\ TEACHING \\ in \\ PHYSICAI EDUCATION
}

Portland State University

1983 
TO THE OFFICE OF GRADUATE STUDIES AND RESEARCH

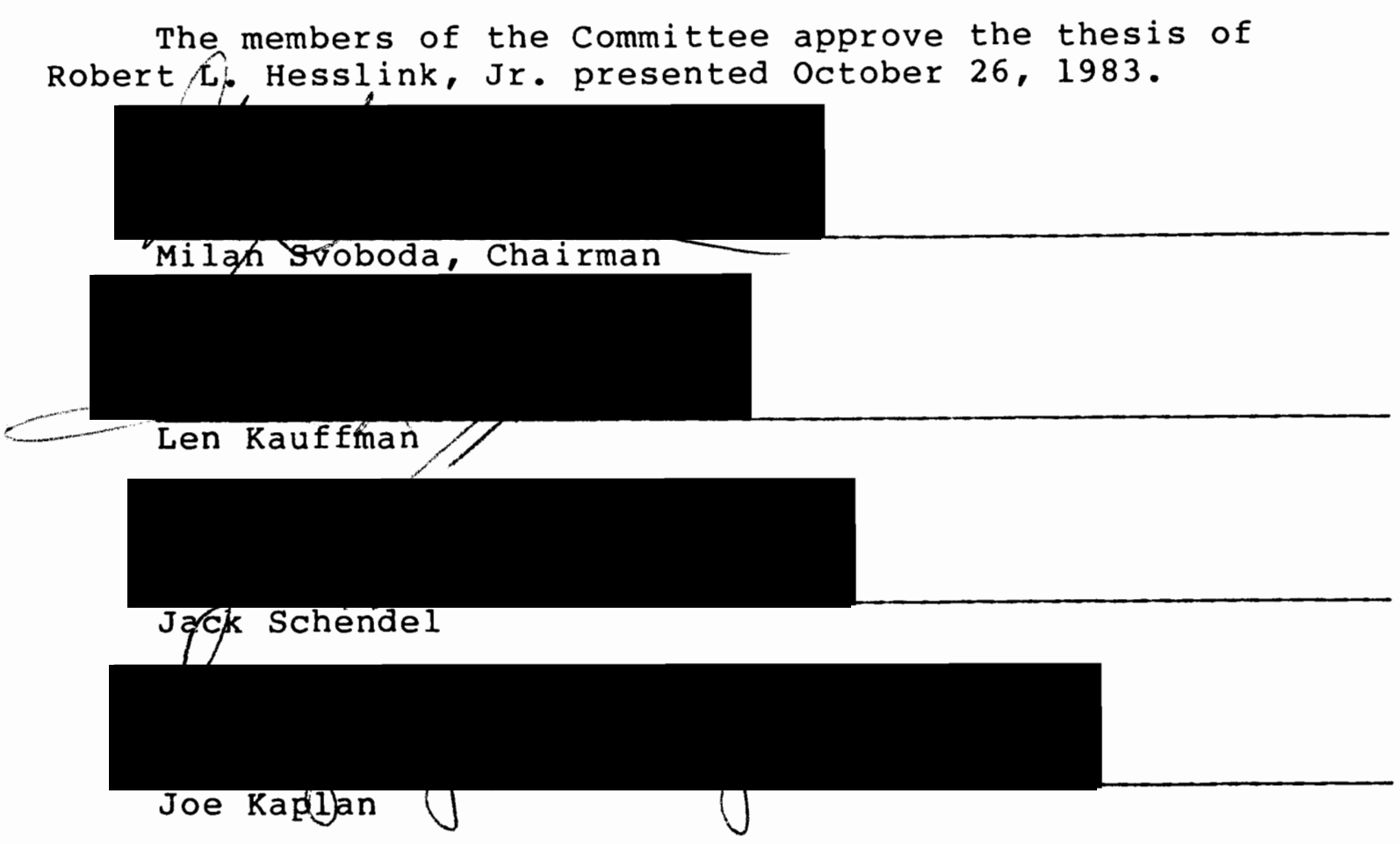

APPROVED :

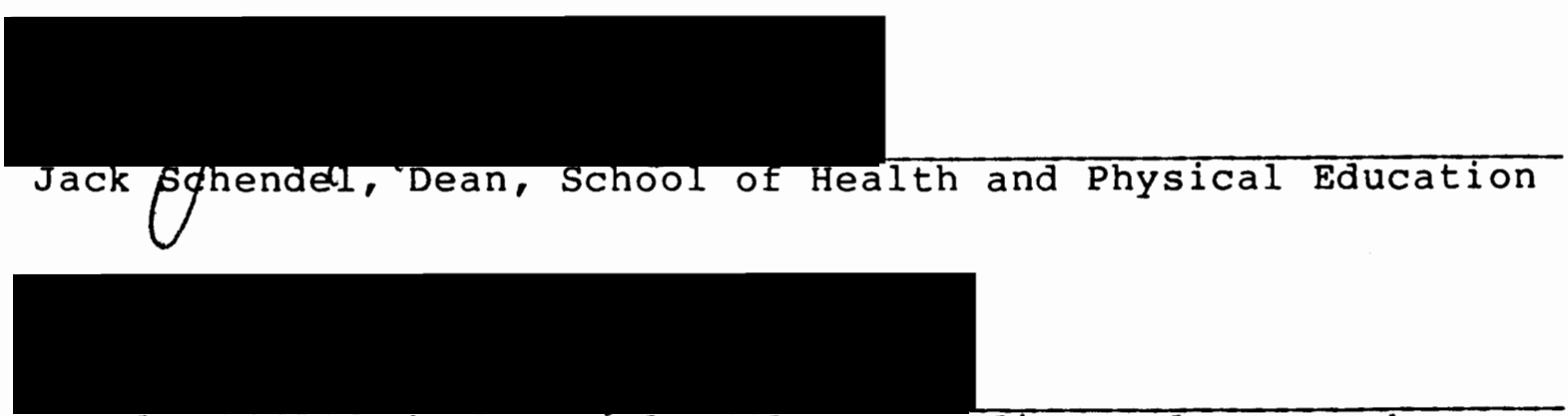

Stanley E. Rauch, Dean of Graduate Studies and Research 
TABLE OF CONTENTS

LIST OF TABLES •. • • • • • • • • • • • • • • • • • vi

CHAPTER

INTRODUCTION • • • • • • • • • • • • • 1

I I REVIEW OF LITERATURE . . . . . . . . . . 5

Effects of weight Training on Body

Composition and Cardiorespiratory Fitness. • 5

Effects of Endurance Training on Body

Composition and Cardiorespiratory Fitness. - 8

Effects of Circuit Weight Training on Body

Composition and Cardiorespiratory Fitness. . 10

Effects of Combined Weight Training and

Endurance Programs on Body Composition and

Cardiorespiratory Fitness. . . . . . 13 
il I StATEMENT OF THE PROBlem . . . . . . . 18

IV RESEARCH DESIGN AND METHODOLOGY. . . • • . 21

Subjects . . . . . . . . . . . . 21

Pre-conditioning . . . . . . . . . 24

Weight Training Program for Group I. . . . 24

Endurance Program for Group II . . . . . 26

Weight and Endurance Program for Group III. 29

Measurement of Cardiorespiratory Fitness • . 31

Measurement of Body Weight and Height . . . 31

Girth and Skinfold Measurement. . . . . . 32

Measurement of Residual Volume. . . . . . 33

Measurement of Body Density . . . . . • 35 
V RESULTS AND DISCUSSION. • • • • • • • • • 37

VI IMPLICATIONS FOR FUTURE RESEARCH. • • • • • 50

LIST OF REFERENCES. . . . . . . . . . . . . 57






\section{LIST OF TABLES}

TABLE

PAGE

I Hypothetical Changes in Body Composition

I Experimental Design

II Pre-conditioning Program

IV Progressive Endurance Program for Group I I

27

V Progressive Endurance Program for Group III 30

VI Descriptive Statistics

VII Training Mileage for Groups II and III

VIII Strength Assessment

IX Cardiorespiratory Fitness 43

$x$ Hydrostatic Weighing Data 
vii

XI Circumference Data 46

$\begin{array}{lll}\text { XII Skinfold Data } & 47\end{array}$

XIII A Comparison of Net Tissue Changes Produced

Through Various Training Programs 


\section{CHAPTER I}

\section{INTRODUCTION}

The concern for cardiovascular health in the late 1960's and early 1970's brought an increased awareness of a need for aerobic conditioning, of which jogging was the primary activity. As the popularity of jogging increased, the attention of the American public shifted away from total body conditioning and emphasis was placed on the maintenance of central core functioning (i.e., the heart). This perspective still persists today as is evident in the low priority given to strength training in exercise prescription literature.

Ideally, an exercise program should be varied and yet still specific to the needs and interests of an individual. In business and scholastic environments, time is an element that cannot be relinquished without loss of financial revenue or knowledge. Therefore, another requirement of all exercise programs is a need to be time-effective. As Wilmore (33, p. 130) writes, "individualized prescription of exercise is now a reality and is being used successfully throughout the United States." If Wilmore's observation is true, then recommendations and knowledge about exercise programs must be accurate and time-effective in meeting the needs of the individual. 
The question of how to obtain an optimal body composition is still not entirely clear. Should one engage only in aerobic exercise to improve body composicion? Cannot weight training activities designed to increase the amount of lean body weight also have a favorable effect on body composition? This study was initiated from personal observations during hydrostatic weighing of athletes who primarily used jogging or running for conditioning purposes. Many such athletes seemed to have a higher percent of body fat than one would expect given their training regimes. This was particularly noteworthy because it also appeared that other athletes who primarily engaged in weight training seemed to have less body fat than those individuals training via aerobic activities. Is it not possible that a combined running and weight training program can elicit more favorable changes in body composition than either method alone? It is to this latter question that the present study is addressed.

Before the Iiterature is reviewed, selected terminology is presented so that precise interpretation of results may be facilitated. These include:

Hypertrophy training -- A weight training program in which 3 sets of 10 repetitions are performed with an intensity equal to $80 \%$ of one repetition maximum . 
Strength training -- A weight training program in which 3 sets of $3-4$ repetitions are performed with an intensity equal to 90-95\% of one repetition maximum.

Circuit training -- A training method in which an individual moves from one exercise station to another performing specified exercises.

Cardiorespiratory fitness -- The ability of the circulatory and respiratory system to efficiently meet imposed demands during all levels of exercise.

Residual volume -- The amount of air that remains in the lungs and respiratory passages after a maximal exhalation.

Absolute fat -- The total amount of body fat found in the human body.

Fat-free weight -- Weight of the body that does not include absolute fat, but consists of bones, muscle, skin, fluids, etc.

Relative fat -- Ratio of absolute fat to total body weight expressed as a percentage.

Combined training program -- A program in which endurance and weight training activities are performed in series within a specified workout during one day. This type of combined program 
differs from an alternating combined program in which weight training and endurance activities are performed on an alternate day basis (i.e. -weight training-MWF; endurance training-TTHS). 


\section{CHAPTER II}

\section{REVIEW OF LITERATURE}

The review of literature will cover research on standard categories of training programs as they affect body composition and cardiorespiratory fitness. The categories include: weight training, endurance training, circuit weight training and combined training.

Effects of Weight Training on Body Composition and CardioRespiratory Fitness

An original study by Nagle and Irwin (23) investigated the effects of weight training on cardiorespiratory fitness. In the study, two groups performed a series of weight training exercises for one hour, 3 days per week for 8 weeks. The exercises included arm curls, military press, pull-overs, bench press, pull-up row, dead-lift, sit-up, squat, toe raises, straddle lift, snatch and triceps extension. The low-repetition high-resistance (LH) group performed 2 sets of 5 repetitions for each exercise and the high-repetition low-resistance (HL) group performed 1 set of 15 repetitions and then 1 set of 12 repetitions for each exercise. The investigators found that $\underline{F}$-ratios obtained for maximum carbon dioxide production $(F=.20)$, maximum 
oxygen consumption $(F=.08)$ and respiratory exchange ratio $(F=.15)$ were not significantly changed after training. Katch and Katch (21) investigated muscular development in body builders, power lifters and olympic weight lifters. The investigators determined boay composition via girth measurements (neck, shoulder, chest abdomen, thigh) and hydrostatic weighing. Residual volume was measured using the oxygen dilution method and relative fat was determined from siri's (28) equation. This study showed that men who had experienced prior weight training had extreme muscle hypertrophy. Relative fat values of 9.3 to $9.7 \%$ were reported which are lean when compared to average values for men which are normally reported to be in the range of $14-158(33, \mathrm{p} 60)$.

Wilmore (32) looked at alterations in body composition after a 10-week weight training program on both male and female volunteers. Two groups performed two 40-minute sessions per week. The exercises included half-squat or dead-1ift, leg press, toe raises, two-arm underhand cur1, standing press, bench press, pull-overs, bent rowing and side bends. Each exercise was performed for 2 sets of 7-9 repetitions and intensity was increased when the subjects could achieve 14-16 repetitions. Body composition was assessed via hydrostatic weighing with residual volume measured through the oxygen dilution method. Relative fat 
was determined using Siri's (28) equation. Skinfold measurements were taken at various sites: chest, mid-axillary, triceps, subscapula, abdominal, suprailiac and thigh. A substantial increase in Eat-free weight was reported for men $(1.19 \mathrm{~kg})$ and women $(1.06 \mathrm{~kg})$. Absolute fat values decreased significantly for both men and women $(.93 \mathrm{~kg}$ and $1.08 \mathrm{~kg})$ respectively.

Misner (22) reported similar findings using a series of 10 progressive resistance exercises covering the major muscle groups: bicep curl, leg press, bench press, sit-ups, leg extension, leg flexion and one exercise of the subject's choice. The intensity was set so that only 3 repetitions could be performed and exercise intensity was increased by 10 pounds per lift when 8 repetitions could be achieved. Body composition was assessed using total body potassium and skinfold techniques (cheek, triceps, subscapula, mid-axillary, suprailiac, abdomen, knee, calf and thigh). The results of this study showed that fat-free weight (FFW) increased by $3.1 \mathrm{~kg}$ and absolute fat decreased by $2.2 \mathrm{~kg}$. The studies reviewed suggest that weight training can provide a substantial alteration of body composition in an 8 to 10 week period. Nagle and Irwin (23) reported that traditional weight training did not enhance cardiorespiratory function. 
Effects of Endurance Training on Body Composition and

Cardiorespiratory Eitness

The benefits of endurance training on the human body have been documented in many research articles $(2,3,5,11,16,18,26,31)$. The outgrowth of these studies is a greater knowledge and understanding of the physiological mechanisms associated with an improvement in cardiorespiratory fitness. These include increased oxidative enzyme activity, increased maximal oxygen consumption, increased mitochondrial content of skeletal and cardiac muscle, an increase in cardiac output and cardiac hypertrophy $(5,16,26)$. Another major benefit associated with endurance training is the alteration of body composition through losses in absolute fat weight with minimal or no change in fat-free weight $(3,11,18,31)$.

Misner (22) investigated the effects of a walk/jog protocol for $30 \mathrm{minutes/day}$ for 8 weeks on body composition. The results showed that fat-free weight increased by $1.3 \mathrm{~kg}$ and absolute fat decreased by $2.3 \mathrm{~kg}$. As reported earlier, Misner also investigated the effects of 8 weeks of weight training on body composition and showed that fat-free weight increased by $3.1 \mathrm{~kg}$ and absolute fat decreased by $2.2 \mathrm{~kg}$. Thus, the endurance program produced a loss in absolute fat with minimal development of fat-free weight while the weight training program produced an increase in fat-free weight and 
a loss in absolute fat. This difference in fat-free weight change was significant at the 0.05 level of confidence. wilmore (31) found that there was no increase in fat-free weight using a walk/jog/run protocol administered 3 times a week for 10 weeks. The subjects were instructed to increase the distance traveled and/or time to complete a given distance during each workout period. Body composition was determined using hydrostatic weighing with residual volume measured via the oxygen dilution method. Siri's equation was used for relative fat determination. The results of this study showed that fat-free weight increased by $.14 \mathrm{~kg}$ and that absolute fat decreased by $1.06 \mathrm{~kg}$. A recent study by Johnson (18) investigated the effects of a 16 week marathon running program on college males. The subjects were instructed in various methods and physiological aspects of marathon running and were encouraged to run six days per week. At the end of the tenth week the subjects were running approximately 50-75 miles per week. Each subject was hydrostatically weighed with residual volume estimated from vital capacity. Brozek's (4) equation was used for relative fat determination. Skinfold sites were taken at the triceps, scapula, mid-axillary, suprailiac, abdomen and thigh. No prediction of body density was made from the skinfold data although all sites showed significant decreases from initial 
values. The results showed that fat-free weight increased by $.11 \mathrm{~kg}$ and that absolute fat decreased by $3.2 \mathrm{~kg}$. The t-ratio for change in absolute fat was significant at the .05 level of confidence, while fat-free weight did not change significantly.

The studies reviewed all suggest varying degrees of absolute fat weight loss due to endurance training. However, there is not a consensus of opinion on alteration in fat-free weight. Some studies reported no change in fat-free weight while one reported a small increase.

Effects of Circuit Weight Training on Body Composition and Cardiorespiratory Fitness

An early study by Allen (1) investigated the effects of circuit weight training (CWT) on cardiorespiratory fitness. Subjects exercised for 30 minutes per day, 3 days per week for 12 weeks. The exercises used were military press, leg curls, overhead chins, lat pull-downs, leg press, bench press and sit-ups. All exercises were performed on a Universal multi-station machine. Each subject performed 3 sets per station $(2$ sets at 8 repetitions and the last set to exhaustion) and worked at a rate which was set at 60 beats per minute to control work time ( 30 seconds) and recovery time (60 seconds). A maximal endurance test was performed by each subject using a bicycle ergometer to 
assess cardiorespiratory fitness. Results showed no significant change for maximal oxygen consumption $(F=.94)$, maximal heart rate $(F=.05)$, maximal cardiac output ( $F=$ $.02)$, maximal stroke volume $(F=.04)$ or maximal arterial-venous oxygen difference $(F=.21)$. Allen concluded that CWT did not adequately stress the cardiorespiratory system to elicit improvement.

Gettman (10). investigated the effects of CWT on cardiorespiratory fitness and body composition. Subjects exercised 3 days/week for 20 weeks. The CWT program was designed such that 2 sets of 15 repetitions were performed for each exercise. Intensity was set at $50 \%$ of one repetition maximum for each exercise. The exercises used were bench press, knee extension, knee flexion, biceps curl, leg press, sit-ups, shoulder press, lat pull down and upright rowing. Body composition was assessed via hydrostatic weighing with residual volume determined by the oxygen dilution method. The subjects performed a treadmill test to ascertain maximum oxygen consumption following procedures outlined by Pollock, et al. (25). Results showed that fat-free weight increased by $1.8 \mathrm{~kg}$ and absolute fat decreased by $1.3 \mathrm{~kg}$. Maximum oxygen consumption increased by $2.6 \mathrm{ml} / \mathrm{kg} / \mathrm{min}$ which was significant at the .05 level of confidence. 
In a more recent study, Gettman (11) investigated isokinetic circuit weight training on body composition and cardiorespiratory fitness. Each subject performed 2 circuits of 10-15 repetitions with 30-second rest intervals for 8 weeks. The exercises used were bench press, lat pull down, knee extension, knee flexion, bicep curl, leg press, sit-up, shoulder press and cycling at $900 \mathrm{kgm} / \mathrm{min}$. Body composition was assessed via hydrostatic weighing with residual volume determined by the oxygen dilution method. Cardiorespiratory fitness was assessed using a treadmill protocol. Results showed that fat-free weight increased by $1.0 \mathrm{~kg}$ and absolute fat decreased by $0.7 \mathrm{~kg}$; neither change was significantly different. Gettman (11) reported a significant increase (3\%) in aerobic capacity for these subjects.

Girandola, et al. (14) investigated the effects of 9 weeks of circuit training on body composition and cardiorespiratory fitress. Subjects performed 3 circuits of calisthenics, running and weight training exercises done 2 days per week. Maximum oxygen consumption was assessed using a cycle ergometer. Body composition was determined from hydrostatic weighing with residual volume measured by the oxygen dilution method. Results showed that fat-free weight increased by $.67 \mathrm{~kg}$ and absolute fat decreased by .84 $\mathrm{kg}$, each change being significant. Maximum oxygen 
consumption increased significantly by $4.2 \mathrm{ml} / \mathrm{kg} / \mathrm{min}$. The articles reviewed suggest that CWT can be an alternative to either traditional weight training or endurance training for alterations in body composition. Allen (1) reported that CWT produced no improvement in cardio-respiratory fitness. However, as Gettman concludes in a recent review (12), more recent studies $(10,11,14)$ suggest that there is minimal improvement in cardiorespiratory fitness with circuit weight training.

Effects of a Combined Training Program on Body Composition and Cardiorespiratory Fitness

Training programs which combine weight training and endurance training together have received minimal research interest to date $(13,15)$. Gettman, et al (13) investigated the effects of a supercircuit program on physiological parameters. A supercircuit program (SC), as defined by Gettman, consisted of multiple weight stations with a short running phase between each station. The running period lasted for 30 -seconds and provided stimulus to the heart and circulo-respiratory system. Exercises consisted of the squat, shoulder press, knee flexion, bench press, leg press, elbow flexion, back hyperextension, elbow extension, sit-ups and vertical flies. Each exercise was performed on a Universal multi-station machine. Intensity was set at $40 \%$ 
of each individual's one repetition maximum for each lift and 12-15 repetitions were performed during the 30-second weight phase. Running intensity was adjusted to elicit and maintain a heart rate within the individual's training heart rate range. Body composition was determined through hydrostatic weighing with residual volume measured from the nitrogen washout procedure. Brozek's (4) equation was used to convert body density units into relative fat. Results showed that there were no significant differences in the changes in body composition when comparing regular CWT and SC programs. In the regular CWT program, fat-free weight increased by $1.21 \mathrm{~kg}$ and absolute fat decreased by $2.31 \mathrm{~kg}$. The SC program produced an increase in fat-free weight of $1.97 \mathrm{~kg}$ and a decrease in absolute fat of $1.87 \mathrm{~kg}$.

The results showed that the regular CWT program elicited an improvement in maximal oxygen consumption of 4.0 $\mathrm{ml} / \mathrm{kg} / \mathrm{min}$. In comparison, the supercircuit program with added running interval elicited an improvement of 5.5 $\mathrm{ml} / \mathrm{kg} / \mathrm{min}$. The difference between the regular CWT and SC programs was not significant, but both were significantly greater than the control group which experienced a change of only $1.0 \mathrm{ml} / \mathrm{kg} / \mathrm{min}$.

In another study, Hickson (15) investigated the effects of a combined strength and endurance program (SE) compared with each method of training performed separately. 
The strength only (S) group consisted of weight training 5 days per week for 10 weeks and was designed to increase leg strength. The exercises included parallel squats, knee flexion, leg press and calf raises. Intensity was set at 80 of the subject's one repetition maximum as determined prior to the study. Additional weight was added to maintain maximal resistance at a specified number of repetitions. The endurance only (E) group exercised 6 days per week for 10 weeks. Experimental protocol was designed such that 3 days per week the subjects did interval training (six 5-minute sessions) on a bicycle ergometer with a 2-minute rest between training sessions. On alternate days subjects performed continuous running with as fast a pace as possible. Running time was initially set at $30 \mathrm{~min} /$ day for the first week, $35 \mathrm{~min} / \mathrm{day}$ the second week and 40 minutes/day thereafter. The SE group performed both activities with a 2 hour rest period between each activity. Skinfolds were taken at the triceps, subscapula, superiliac, pectoral and thigh sites using procedures described by Yuhasz (35) to determine relative fat. The results showed that all three groups experienced a significant increase in fat-free weight: $S$ group $(+1.2 \mathrm{~kg})$, E group $(+0.9 \mathrm{~kg}), \mathrm{SE}$ group $(+1.2 \mathrm{~kg})$. Also, all three groups experienced a significant decrease in absolute fat: $S$ group $(-0.3 \mathrm{~kg}), E$ group $(-3.1 \mathrm{~kg}), \mathrm{SE}$ group $(-2.0 \mathrm{~kg})$. Both the $\mathrm{SE}$ and $\mathrm{E}$ 
Groups experienced significant improvements in maximal oxygen consumption $(7.4$ and $8.6 \mathrm{ml} / \mathrm{kg} / \mathrm{min}$; respectively). The $\mathrm{S}$ group $(0.7 \mathrm{ml} / \mathrm{kg} / \mathrm{min})$ had minimal improvement.

The two studies which investigated combined training programs yielded conflicting results regarding changes in body composition. This conflict may be a direct result of different training methodologies and/or differences in experimental design. Neither of these studies equated the total exercise time required for either weight or endurance training with that of the combined approach (i.e. -- 40 minutes of running or 40 minutes of weight training vs. 20 minutes of running and 20 minutes of weight training). Of the two combined studies reviewed, Gettman's (13) study utilized two methods (regular CWT and SC) which are reasonably similar in their exercise requirements and both require less than 30 minutes of time. In Hickson's (15) study, the amount of exercise time performed by the SE group (close to $31 / 2$ hours) is not practical for the average person.

In summary, the review of literature indicates that weight training, either through use of traditional free-weights or circuit weight training, produces an increase in fat-free weight and a decrease in relative body fat. Also noted is that endurance training produces an increase in cardiorespiratory fitness along with decreased 
amounts of absolute fat. Circuit weight training has been shown to produce moderate increases in cardiorespiratory fitness whereas traditional weight training does not. The two studies investigating the combined effects of weight and endurance training reported conflicting results with regard to changes in body composition.

Given the fact that there is a limited amount of research data concerning the effects of a combined training program on body composition leads to support for continued investigation in this area. The present study is designed to address some major questions regarding combined training programs. 


\section{CHAPTER III}

\section{STATEMENT OF THE PROBLEM}

The standard method for determining the success of an exercise program with regard to alterations in body composition has been to evaluate changes in relative fat. While altered relative fat values do reflect the overall changes in body composition which may occur, the nature of such changes are not clearly apparent. It is quite possible that a reduction in relative fat can be produced entirely by losses in absolute fat, by gains in fat-free weight or by changes in both. Table I provides a descriptive account of how such hypothetical body tissue changes can affect relative fat.

Although it is well documented that a loss of absolute fat has a significant effect on relative fat there is reason to speculate that a combined loss of absolute fat and gain of fat-free weight may be more beneficial to the health and well-being of the individual. From Table I, the net effect of the combined changes on relative fat is nearly as great as through a loss of absolute fat alone (13.6\% vs. $12.5 \%$ ). Yet, one could argue that the development of fat-free weight is more beneficial to the individual due to the many factors associated with increased fat-free weight (i.e., increased 


\section{TABLE I}

HYPOTHETICAL CHANGES IN BODY COMPOSITION

Parameter Initial

Loss of
$\mathrm{AF}^{1}$

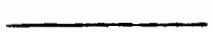

Body

weight

Relative

fat

Absolute

fat $(\mathrm{kg})$

FFW ( kg)

$15.0 \%$

$12.5 \%$

$68 \mathrm{~kg}$

14.68

$13.6 \%$

Gain of

Combined

change ${ }^{3}$

$72 \mathrm{~kg}$

$70 \mathrm{~kg}$

$70 \mathrm{~kg}$ 
strength, increased caloric expenditure, greater ability to survive emergencies and enhanced appearance).

The review of literature has reported that endurance activities elicit primarily a loss of absolute fat, thereby causing a reduction in relative fat. Weight training activities produce gains in fat-free weight which also can cause a reduction in relative fat on the basis of the logic in Table I. This leads to the question to which this study is addressed:

Can a combined training program elicit more favorable changes in body composition than either method of training alone?

Restated for statistical purposes it is hypothesized that:

$\mathrm{H}_{0}$ : When experimental and control group scores are compared, there will be no significant difference between the group means for body weight $(\mathrm{kg})$, absolute fat $(\mathrm{kg})$ and fat-free weight $(\mathrm{kg})$. 
CHAPTER IV

\section{RESEARCH DESIGN AND METHODOLOGY}

\section{RESEARCH DESIGN}

The experimental design is presented in Table II and involved four separate groups: 3 treatment groups which trained and 1 control group which remained sedentary. The study was designed such that total training time for all groups is limited to 40-minutes per day, three days per week.

\section{SUBJECTS}

Subjects were 21 male volunteers from the Portland metropolitan community. The recruitment of the volunteers was initiated from bulletin board flyers that had been posted throughout the Portland State University campus. To be accepted into the study each subject had to be available from 8:30 a.m. until 10:00 a.m. Monday-Wednesday-Friday for 10-weeks, be within the ages of $18-30$ years and not be actively involved in physical activity. All subjects were screened to assure a history of a sedentary lifestyle during the prior 3 months as determined from responses to an initial questionnaire and interview (See Appendix A for a copy of questionnaire). 
TABLE II

\section{EXPERIMENTAL DESIGN}

Group

I

I I

I I I

IV
Treatment

Weight training

Endurance training

Combined:

Endurance and

Weight training

$40 \mathrm{minutes}$

40 minutes

40 minutes

Training Time

ro minutes

40 minutes

Control 
Subjects were randomly assigned to one of three groups. The selection procedure required each subject to pick a slip of paper from a box of 21 slips, seven each with the numbers I, II or III written on them. Subjects were assigned to the particular group that corresponded with their number. Each of three training groups began with seven subjects per group. A control group was selected from students who had been interested in the research study but could not meet the daily time requirement. Others were recruited from physical education classes at Portland State University which provided minimal or no vigorous activity (i.e., archery, bowling, golf, etc.). Control subjects agreed not to participate in any training or physical activity during the course of the 10-week study.

Treatment subjects were not placed in their respective groups until after a 3 -week pre-conditioning program (see Pre-conditioning below). Diet was not controlled due to the variability of schedules, economic factors and time involvement. Subjects were encouraged not to alter knowingly caloric intake but to use a perceived need of food as the criterion for extra caloric intake if extra food seemed appropriate. All subjects (treatment and control) were instructed as to the benefits and risks of participating in the study and informed consent was received prior to subject involvement (See Appendix B for a copy of 
informed consent form). Procedures used in the study were approved by the Portland State University Human Subjects Research Committee.

\section{PRE-CONDITIONING}

Treatment groups were administered a pre-conditioning program (See Table III) in order to strengthen the knee stabilizers (i.e., quadriceps and hamstrings) and low-back region to prevent injury during the experimental period. Subjects were also instructed on the correct technique for performing the three major lifts in the study. Subjects were given at least two sessions in which to familiarize themselves with each technique.

\section{WEIGHT TRAINING PROGRAM FOR GROUP I}

The weight exercise program consisted of a 40-minute training session, 3 days per week for 10-weeks. The program was designed to produce maximum muscle hypertrophy. Exercises included parallel squat, bench press and dead-lift. Each lift was attempted for 5 sets of 8-10 repetitions. Initial intensity was set at $80 \%$ of the 
TABLE III

PRE-CONDITIONING PROGRAM

Exercise Intensity Frequency Duration

Leg

Extension 30 pounds $M-W-F \quad 3$ sets of 10 repetitions

Leg

Flexion $\quad 10$ pounds $M-W-F \quad 3$ sets of 10 repetitions

Abdominal

Cur 1

-- $\quad M-W-F$

3 sets of 25 repetitions

Low-back

raises

$--\quad M-W-F$

3 sets of 10 repetitions 
subject's one repetition maximum for each lift. Weight was increased by 5-pounds on the bench press and 10-pounds for both the squat and dead-lift when a subject was able to achieve two full training sessions with 50 repetitions per exercise. The sets were separated by one-minute recovery periods. All lifts were performed using olympic-style free weights in the weight room at Portland State University. All training sessions were supervised and weight lifting belts were available for use by the subjects.

ENDURANCE PROGRAM FOR GROUP II

The endurance exercise program consisted of 40-minute sessions, 3 days per week for 10-weeks following the walk/run progression presented in Table IV. The program consisted of continuous movement in a gymnasium (circumference $=276$ feet) for 5 weeks. For the remaining 5 weeks subjects ran on a running track ( 1 lap $=1 / 8$ th of a mile) located on top of the physical education building at Portland State University.

The indoor facility was utilized initially because of environmental factors during the winter months. Subjects were instructed in measuring heart rate via radial or 
TABLE IV

PROGRESSIVE ENDURANCE PROGRAM FOR GROUP II*

Week

1

2

3

4

5

6

slow run time (min.)
Slow run time (min.)

5

6

7

8

9

10

$\begin{array}{rrr}7 & 5 & 5 \\ 8 & 3 & 7 \\ 9 & 1 & 9 \\ 10 & 0 & 10\end{array}$

*Each day of exercise, the 40 minute session was divided into blocks of 10 minutes each and repeated four times. These 10-minute blocks are outlined in this table. 
carotid pulse and educated in physiological principles of cardiovascular conditioning. Each subject recorded a resting heart rate prior to sleep for 5 consecutive days. The average was used to determine a training heart rate (THR) by the method of Karvonen (19):

$$
\begin{aligned}
& \text { THR = resting } H R+(\text { maximum } H R \text { - rest } H R)(.6) \\
& \text { where, } H R=\text { heart rate } \\
& \text { maximum } H R=220 \text { - age }
\end{aligned}
$$

Subjects were instructed to obtain a 15-second pulse count during the first walk phase of a training session for the initial six sessions. This procedure was implemented so subjects could determine a walking pace that would elicit their THR. In addition, at the end of every third training session subjects obtained a 15-second pulse count for comparison with their THR. Subjects adjusted their training pace according to this final heart rate, thereby insuring that a heart rate which approximated each subject's individual THR was achieved during each daily session. Each subject was given a grocery hand counter to be used for monitoring the number of laps performed each day.

Subjects were given a demonstration on the difference between walking and running. Walking was defined as having the center of mass evenly placed above the base of support and using large arm and leg movements. Running was described subjectively as occurring when the subject felt it 
more efficient and comfortable to run (with slight forward lean) than to walk at a given pace. During the last four weeks of the study subjects were asked to increase their running speed. Intensity of this new running component was to be approximately $25 \%$ faster than their slower running pace. The additional component was implemented so the subjects would maintain an adequate training stimulus during the last four weeks of the study. Subjects used their training heart rate to determine their given pace for all phases of endurance training.

\section{WEIGHT AND ENDURANCE PROGRAM FOR GROUP III}

Subjects in this group performed the same weight exercises (parallel squat, bench press, dead-lift) as the subjects in group I except they attempted 3 sets of $8-10$ repetitions in twenty minutes. Intensity was determined and maintained as explained in the Weight section for group I. Subjects performed the endurance phase for twenty minutes immediately following the weight training phase. A one-minute rest period was allowed while changing from weight training to endurance training. Subjects followed all procedures as explained in the Endurance section for group II and used the walk/run progression presented in Table V. 
TABLE V

PROGRESSIVE ENDURANCE PROGRAM FOR GROUP III*

$\begin{array}{ccc}\text { Week } & \text { Walk time (min.) } & \text { Slow run time (min.) } \\ 1 & 2.5 & 2.5 \\ 2 & 2.0 & 3.0 \\ 3 & 1.5 & 3.5 \\ 4 & 1.0 & 4.0 \\ 5 & 0.5 & 4.5 \\ 6 & 0.0 & 5.0 \\ & & \\ & \text { Slow run time (min.) } & \text { Fast run time (min.) } \\ 7 & 2.5 & 2.5 \\ 8 & 1.5 & 3.5 \\ 9 & 0.5 & 4.5 \\ 10 & 0.0 & 5.0\end{array}$

*Each day of exercise, the 20 minute session was divided into blocks of 5 minutes each and repeated four times. These 5 minute blocks are outlined in this table. 


\section{MEASUREMENT OF CARDIORESPIRATORY FITNESS}

Maximal oxygen consumption was estimated from heart rate response to the Harvard step test as modified by Sharkey (27). The subjects were familiarized with the bench height ( 15.75 inches) and metronome count (90 bpm) during the pre-conditioning phase. Subjects were instructed to sit-down for 5-minutes prior to administration of the test. Heart rates were obtained by using a stethoscope placed medially to the left nipple. The subject was then told to begin and continue the test for 5 minutes. At completion he was instructed to sit down. The investigator waited 15-seconds after completion of the stepping and then obtained a 15-second pulse count. Heart rate response was used to predict the individual's maximum oxygen consumption from a table prepared by Sharkey (27).

\section{MEASUREMENT OF BODY WEIGHT AND HEIGHT}

Body weight was assessed in kilograms on a Homs Balance Beam scale with an accuracy to 10 grams. Height was measured in inches from the apparatus located on a standard Continental scale and then converted to meters. 


\section{GIRTH AND SKINFOLD MEASUREMENTS}

Several girth measurements were taken using a Lufkin steel tape. Measurements included upper arm, forearm and abdomen. All were taken from the largest circumference as determined by the investigator through visual identification. Relative fat was determined using the methods of Katch and McArdle (20) with inches converted into constants for use in the equation below:

Relative fat $=$ Constant $A+$ Constant $B$ - Constant C - Age Constant

where, Constant $\mathrm{A}=$ Upper Arm Circumference

Constant $B=$ Abdominal Circumference

Constant $C=$ Forearm Circumference

Age Constant $=10.2$

Skinfolds were measured using Lange calipers at the following sites:

Chest - A diagonal fold halfway between the axillary fold and the right nipple.

Abdominal - A vertical fold taken one-inch to the right of the umbilicus.

Thigh - A vertical fold taken at the proximal anterior one-third region of the thigh at the mid-section of the leg. 
All sites were estimated by the investgator following the anatomical descriptions explained above. Body density $\left(D_{b}\right)$ was determined by the methods of Jackson and Pollock (17) :

$$
\begin{aligned}
D_{b}=1.1093800- & .0008276\left(x_{1}\right)+.0000016\left(x_{1}\right)^{2} \\
-.0002572\left(x_{2}\right) & \text { shere, } x_{1}= \\
& \text { skinfof the thigh, abdomen and chest } \\
x_{2}= & \text { age of the subject }
\end{aligned}
$$

Relative fat was determined using Siri's (28) equation:

$$
\text { Relative fat }=\left(4.95 / D_{b}-4.5\right) \times 100 \text {. }
$$

\section{MEASUREMENT OF RESIDUAL VOLUME}

The equation for determination of residual volume was the oxygen dilution method as modified by wilmore (34). Each subject was required to exhale to residual volume through forced expiration with a standard 3-way mouthpiece in his mouth. When the subject had reached residual volume, the mouthpiece was switched so the subject began breathing from a 5-liter anesthesia bag filled wtih $100 \%$ oxygen (accuracy $=.03 \%)$. After seven full inspirations and expirations the subject was required to exhale to residual volume and the mouthpiece closed. Gas in the bag was then 
analyzed for oxygen and carbon dioxide concentrations with a calibrated Beckman Model E-2 Oxygen Analyzer and Beckman LB-1 Carbon Dioxide Analyzer. Calibration of each instrument was performed using standard gases which had been analyzed by an external lab. Two residual volume determinations were obtained at the time of each subject's hydrostatic weighing with the average of the two measures being used as the subject's score. All values were corrected to and reported under standard conditions. The formula used to compute residual volume was:

$$
\mathrm{RV}=\frac{\mathrm{VO}_{2} \times \mathrm{b}}{79.8-\mathrm{b}}
$$

where, $\mathrm{RV}=$ residual volume

$\mathrm{VO}_{2}=$ volume of oxygen in the bag at beginning of the procedure

$\mathrm{b}=$ percent nitrogen in the mixed air in the bag at point of equilibrium $\left(100 \%-\left(\mathrm{s}_{2}+\mathrm{s}_{2} \mathrm{CO}_{2}\right)\right)$ 


\section{MEASUREMENT OF BODY DENSITY}

The hydrostatic weighing procedure was performed in a stationary tank (58" $\times 37 " \times 54 ")$ with water temperature maintained between 28 and 32 degrees Celsius. Water density was obtained from standard density/temperature tables located in the Handbook of Chemistry and Physics (6). The tank was checked for purity and chlorination on a daily basis. Subjects were instructed on the procedure of expelling air from the lungs while submerging themselves underwater. Each subject sat on a submerged metal chair which was supported by a standard Chatillion autopsy scale. All values were reported in kilograms to the nearest 10 grams. To eliminate learning errors associated with the underwater procedure, each subject was weighed 10 times. The average of the last three trials was used in a modification of Brozek's (4) equation to determine body density:

$$
\begin{aligned}
& D_{b}=\frac{\text { Weight }}{\text { (Weight }} \\
& \text { water density }
\end{aligned}
$$

Relative fat was determined from Siri's (28) equation listed previously. 


\section{STATISTICAL TREATMENT}

Post-test scores were analyzed using analysis of covariance (ANCOVA) to remove the influence of pre-test scores (24). This particular treatment was chosen for reasons listed below (8):

1. To control for randomized groups of unequal N's.

2. To reduce within group (error) variance, increasing the power of the statistical test to account for a small sample size.

In cases where a significant $\underline{F-r a t i o}$ was found, Tukey's Honestly Significant Different procedure (30) was chosen for all pairwise mean comparisons as this treatment is applicable to unequal sample sizes. 


\section{CHAPTER V}

\section{RESULTS AND DISCUSSION}

Descriptive characteristics of the subjects are presented in Table VI. The number of subjects in each group diminished through the course of the study and the final total for each group was: Group I, $n=3$; Group II, $n=4$; Group III, $n=3 ;$ Group IV, $n=4$. The loss of subjects was due to a variety of factors as explained below:

1) Two subjects dropped out during the first 3-weeks of the study. The response given by these subjects was that the structure of the class setting was too rigid and the experimental group which each had been assigned to did not fit their wishes.

2) Two subjects dropped out due to stress fractures of the foot. In each case the subject had developed the condition prior to the study and aggravated the condition while running in the study

3) Two subjects dropped out due to heavy academic class loads and felt that the time devoted to the study interfered with academic study time.

4) One subject participated in eight weeks of the study and then never reported back. 
TABLE VI

DESCRIPTIVE STATISTICS

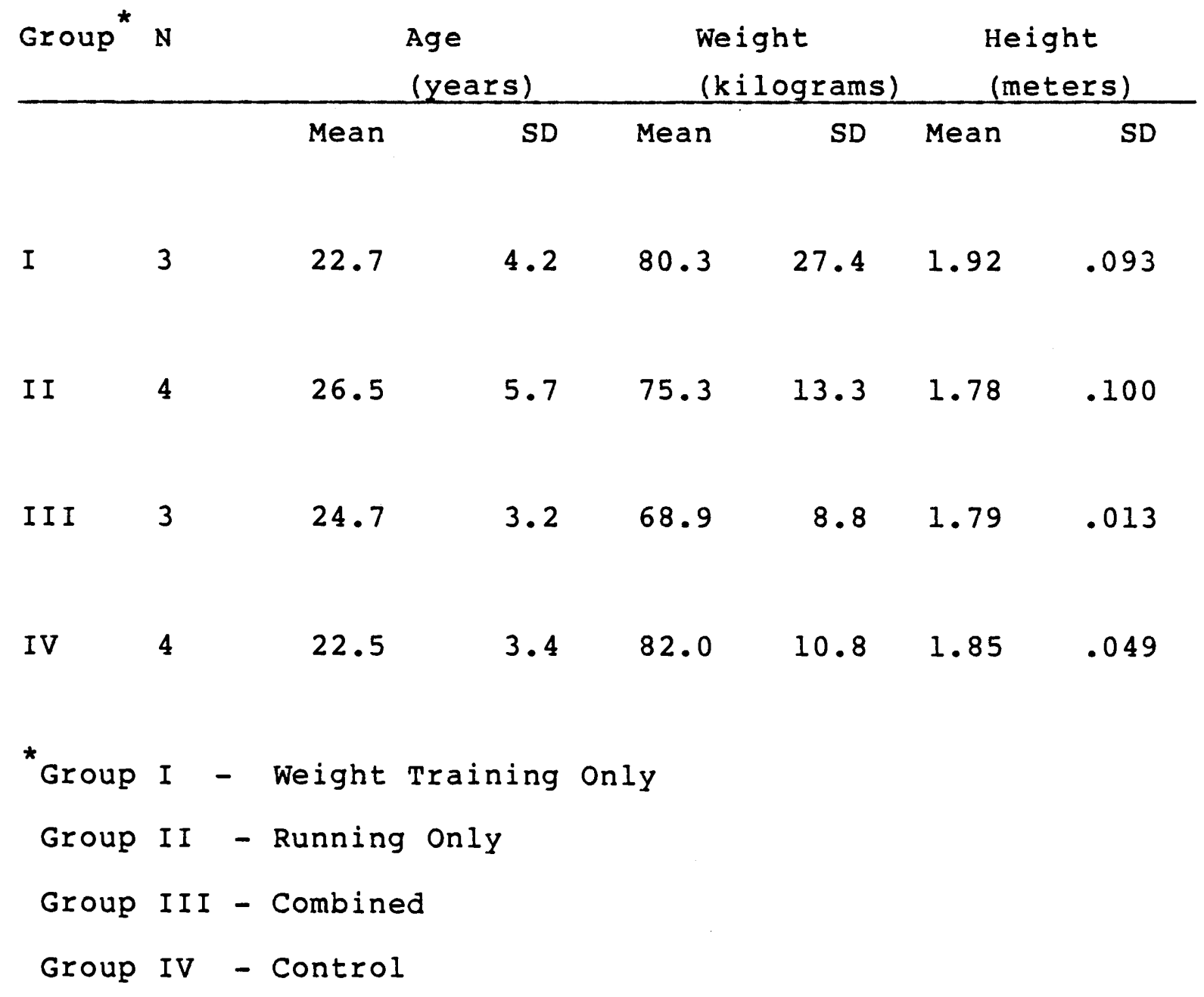


Mean age of each group was similar with the endurance group having the highest value. Body weights obtained showed that the control subjects had the highest average of all four groups. Heights for all groups were very similar.

Table VII presents data of training mileage in groups II and III. Both groups progressively increased in training mileage through the course of the experiment. The average mileage/session of the endurance group ( $4.25 \mathrm{miles})$ was almost twice that of the combined group $(2.25$ miles $)$. This suggests that both groups maintained similar running speeds. Data regarding strength assessment is presented in Table VIII. Using ANCOVA procedures described previously, a significant $\underline{F}$-ratio was found on the parallel squat ( $F=$ 149.5, $p<.02)$. The mean for the weight training group was significantly greater than that of the endurance group ( $q=$ -5.8 with $a^{\prime} q= \pm 4.41$ needed at the .05 level of confidence) using Tukey's procedure. However, it was not significantly different from the mean of the combined group ( $q=-2.4)$. The $\underline{E}$-ratio for the bench press was significant $(F=8.4, p$ $<.02)$ but none of the group means were significantly different from each other using Tukey's procedure. The F-ratio $(F=.16, p<.89)$ for the deadift was not significant.

Subjects were reticent about pushing themselves on the dead-lift despite motivation provided by the investigator. 
TABLE VII

TRAINING MILEAGE FOR ENDURANCE TRAINING GROUPS

Week Group III (miles/session)

Mean

SD

Group II (miles/session)

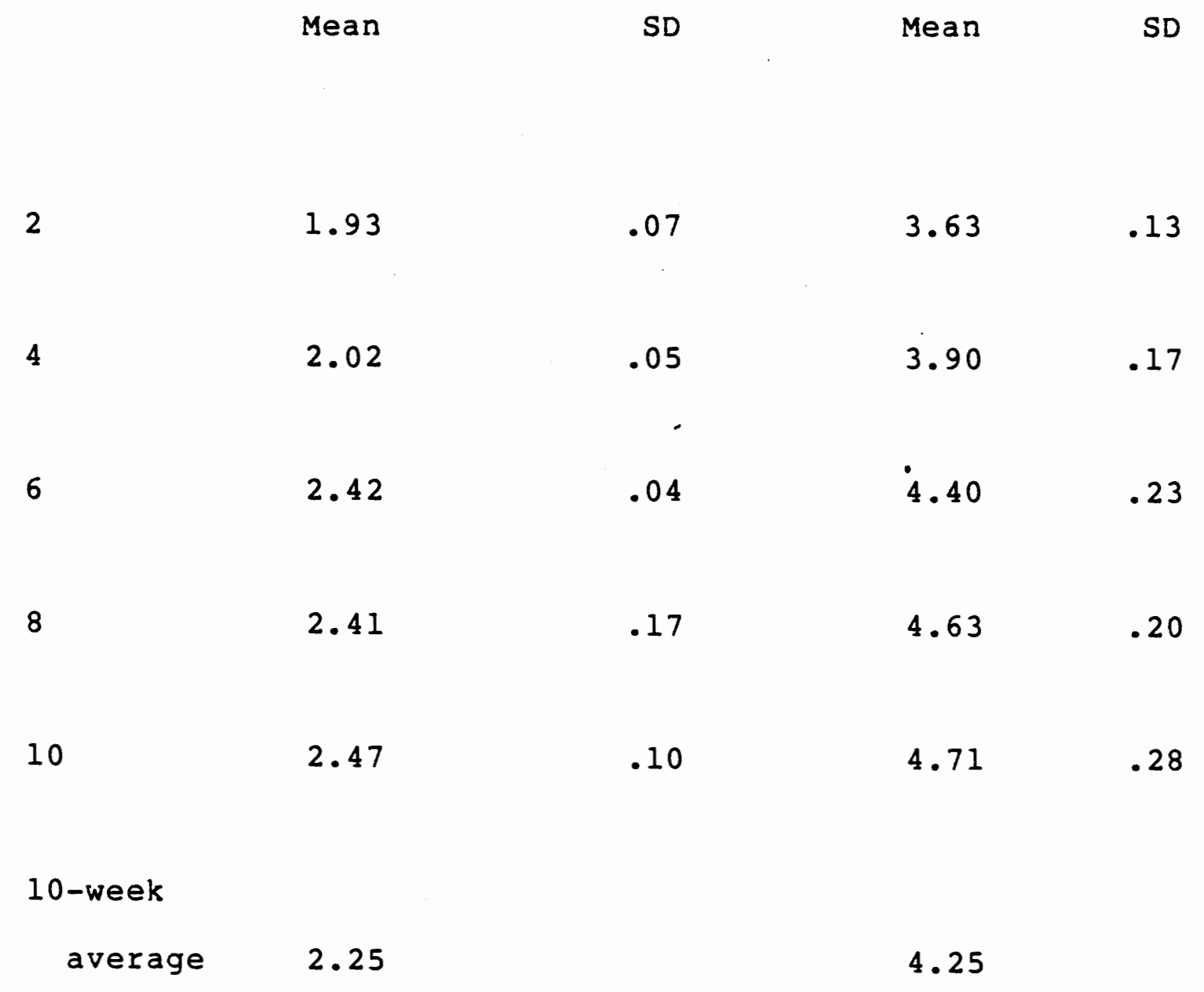

Average mile

time (min.) 9:28

$9: 41$ 
TABLE VIII

STRENGTH ASSESSMENT

Parameter

Group

Pre

Post

Adjusted

Post \#

Mean

SD

Mean

SD

Mean

Squat (1bs)

$\begin{array}{cccccc}\text { I* } & 155.0 & 14.1 & 235.0 & 28.3 & 274.2 \\ \text { I I } & 195.0 & 24.1 & 215.0 & 34.6 & 196.6 \\ \text { I I I } & 183.3 & 29.3 & 246.7 & 40.7 & 245.1\end{array}$

$\begin{array}{lllllll}\text { Bench Press (lbs) I* } & 107.5 & 10.6 & 152.5 & 10.1 & 184.7\end{array}$

I I $\quad 150.0 \quad 32.4 \quad 145.0 \quad 35.6 \quad 136.4$

I I $\quad \begin{array}{lllll}152.0 & 56.7 & 181.7 & 55.1 & 171.5\end{array}$

Dead-lift (lbs) I* $258.0 \quad 24.0 \quad 280.0 \quad 49.5 \quad 306.4$

I I $\quad 302.5 \quad 42.1 \quad 310.0 \quad 47.2 \quad 297.8$

I I $\quad 290.0 \quad 27.8 \quad 290.0 \quad 43.9 \quad 288.9$

\# Post-test scores adjusted for differences in pre-test scores

Data for the weight training group (I) is based on $\mathrm{N}=2$ because collection of the data for one subject at the beginning of the study was incomplete 
This hesitance can possibly be a direct result of the experience associated with the dead-lift on the pre-test and the subject's resulting fear of injury. Therefore, results probably do not reflect true strength improvements. It should be noted that in the squat and bench press, the weight training group was not significantly greater than the combined group. This suggests that 20 -minutes of weight training may be significant to cause a substantial improvement in strength in at least two regions of the body. Data regarding cardiorespiratory fitness is presented in Table IX. A significant F-ratio was found for heart rate response $(F=6.5, p<.01)$. When analyzed using Tukey's test, the combined group mean was significantly lower than those of both the control group $(q=5.2$ with a $q= \pm 4.6$ needed at the .05 level of confidence) and the weight training group $(q=4.8)$, but it was not significantly different from the mean of the endurance group $(q=-2.5)$. Surprisingly, the mean of the endurance group was not significantly different from that of the control group ( $q=$ 2.9), which is difficult to explain.

Data regarding body compositión assessment as measured via hydrostatic weighing is presented in Table $x$. A significant $\underline{F}$-ratio was found for fat-free weight ( $F=5.3$, p $<.02)^{\prime}$. When analyzed using Tukey's procedure the only pairwise comparison which achieved significance was the 


\section{TABLE IX}

CARDIORESPIRATORY EITNESS

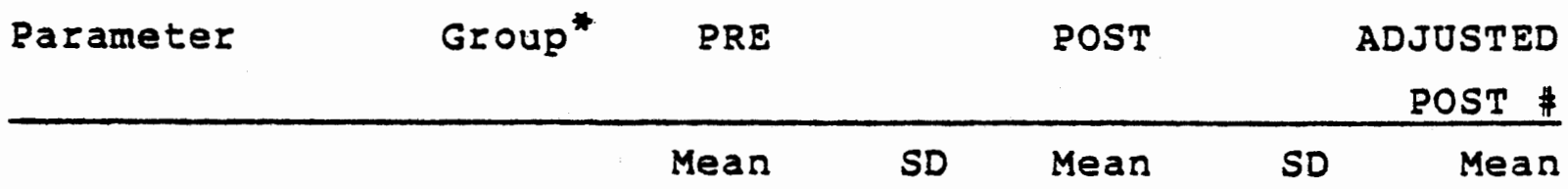

Heart rate

response

(15s count)

$\begin{array}{rlllll}\text { I } & 30.0 & 7.8 & 32.7 & 7.1 & 34.7 \\ \text { II } & 35.7 & 7.5 & 32.3 & 3.8 & 30.2 \\ \text { II I } & 31.4 & 3.3 & 26.0 & 1.7 & 26.0 \\ \text { IV } & 32.1 & 5.4 & 34.3 & 6.1 & 34.8\end{array}$

Estimated maximal

$\begin{array}{rrrrrrr}\text { vo }^{2}(\mathrm{mI} / \mathrm{kg} / \mathrm{min}) & \text { I } & 51.0 & 11.2 & 47.0 & 7.9 & 43.7 \\ & \text { II } & 41.7 & 7.3 & 45.7 & 5.7 & 48.6 \\ & \text { III } & 47.7 & 4.1 & 56.3 & 3.8 & 56.3 \\ & \text { IV } & 46.5 & 6.8 & 44.5 & 6.8 & 44.2\end{array}$

\# Post-test scores adjusted for pre-test scores.

* See Table VI. page 38 for Group identification. 
TABLE X

HYDROSTATIC WEIGHING DATA



\# Post-test scores adjusted for differences in pre-test. 
weight training group versus the endurance group $(q=-4.6$ with $q= \pm 4.6$ needed at the .05 level of confidence). F-ratios for absolute fat $(F=.02, p<.89)$, total body weight $(F=1.8, p<.22)$ and body density $(F=.35, p<$ .78) were not significantly different. Since the weight training group did experience an increase in fat-free weight it is possible that this had a residual effect on metabolic costs over-and-above those associated with the caloric cost of the exercise sessions. An increased fat-free weight could result in a greater caloric expenditure over a 24-hour period as it is related to basal metabolic rate (29).

Data regarding body composition parameters as measured via circumferences (Katch and McArdle method) are presented in Table XI. There were no significant differences found for either absolute fat $(F=.46, p<71)$, fat-free weight $(F=.48, p<.70)$ or circumference sum $(F=.48, p<.70)$. The changes noted earlier in fat-free weight using hydrostatic weighing were not visible using the circumference method. This discrepancy might suggest that the circumference method is less sensitive to subtle changes in body composition.

Data regarding body composition parameters as measured via skinfold measurements are presented in Table XII. No significant differences between groups were found for absolute fat $(F=.63, p<.62)$, fat-free weight $(F=1.5$, 
TABLE XI

\section{CIRCOMFERENCE DATA}

PRE

POST

ADJUSTED POST \#

\begin{tabular}{|c|c|c|c|c|c|c|c|}
\hline & & & Mean & SD & Mean & SD & Mean \\
\hline \multirow[t]{4}{*}{ Relative } & Fat (\%) & I & 18.3 & 11.6 & 18.3 & 10.9 & -- \\
\hline & & I I & 17.4 & 5.7 & 17.0 & 5.7 & -- \\
\hline & & III & 15.4 & 2.5 & 16.8 & 1.5 & -- \\
\hline & & IV & 19.5 & 4.8 & 20.1 & 5.4 & -- \\
\hline \multirow[t]{4}{*}{ Absolute } & Fat $(\mathrm{kg})$ & I & 16.6 & 15.8 & 16.9 & 14.9 & 14.7 \\
\hline & & I I & 13.5 & 6.8 & 13.1 & 6.7 & 13.9 \\
\hline & & I I I & 10.7 & 2.9 & 12.1 & 2.1 & 15.6 \\
\hline & & IV & 16.2 & 5.4 & 16.7 & 7.0 & 14.9 \\
\hline
\end{tabular}

Fat-free

Weight (kg)

$\begin{array}{rrrrrr}\text { I } & 63.7 & 13.4 & 65.8 & 12.7 & 65.3 \\ \text { II } & 61.8 & 7.5 & 60.9 & 6.5 & 60.5 \\ \text { III } & 58.2 & 5.9 & 59.8 & 4.1 & 59.8 \\ \text { IV } & 51.8 & 25.3 & 64.2 & 6.0 & 65.0\end{array}$

Circumference sum (cm)

$\begin{array}{rlllll}\text { I } & 237.3 & 41.4 & 241.3 & 42.9 & 240.7 \\ \text { I I } & 235.6 & 16.1 & 232.4 & 20.7 & 233.6 \\ \text { I I } & 229.2 & 20.2 & 227.3 & 10.9 & 234.9 \\ \text { IV } & 243.3 & 13.4 & 245.5 & 20.1 & 238.9\end{array}$

Post-test scores adjusted for differences in pre-test. See Table VI, page 38 for Group identification. 
TABLE XII

SKINFOLD DATA

Parameter

Group PRE

POST

ADJUSTED POST \#

Mean

SD Mean

SD

Relative Fat ( $z)$

$\begin{array}{rcrrr}\text { I } & 13.3 & 6.3 & 13.5 & 11.8 \\ \text { II } & 13.6 & 6.3 & 14.4 & 5.3 \\ \text { I I I } & 9.51 & 2.3 & 10.6 & 2.9 \\ \text { IV } & 18.0 & 6.1 & 16.9 & 4.9\end{array}$

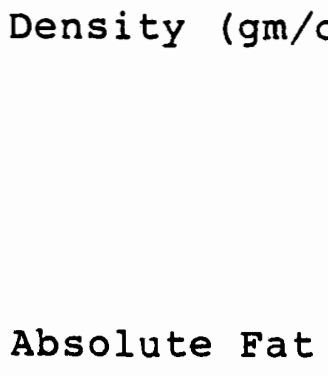

$\begin{array}{rllll}\text { I } & 1.0684 & .02 & 1.0679 & .01 \\ \text { II } & 1.0677 & .03 & 1.0658 & .07 \\ \text { I I I } & 1.0772 & .05 & 1.0746 & .05 \\ \text { IV } & 1.0576 & .07 & 1.0601 & .03\end{array}$

$(\mathrm{kg})$

$\begin{array}{rrrrrr}\text { I } & 12.9 & 14.9 & 13.2 & 14.4 & 11.9 \\ \text { II } & 10.7 & 6.6 & 11.0 & 5.8 & 11.8 \\ \text { I I I } & 6.6 & 1.9 & 7.7 & 2.4 & 12.3 \\ \text { IV } & 15.1 & 6.7 & 14.6 & 5.9 & 11.3\end{array}$

Fat-free

Weight $(\mathrm{kg})$

$\begin{array}{rrrrrr}\text { I } & 67.4 & 13.2 & 69.6 & 12.9 & 67.8 \\ \text { II } & 64.6 & 8.2 & 62.9 & 7.8 & 63.6 \\ \text { II I } & 62.3 & 7.6 & 64.3 & 4.9 & 67.0 \\ \text { IV } & 66.9 & 6.6 & 66.3 & 6.7 & 64.9\end{array}$

Skinfold Sum

$\begin{array}{rr}\text { I } & 96.8 \\ \text { I I } & 80.7 \\ \text { I I I } & 61.1 \\ \text { IV } & 109.1\end{array}$

$79.6 \quad 93.9$

73.2

84.6

(mm)

$30.6 \quad 86.1$

26.9

91.9

$13.0 \quad 63.3$

12.3

92.5

$40.8 \quad 112.3$

43.7

91.6 
$\mathrm{p}<.28)$ or skinfold sum $(F=.48, p<.70)$. The skinfold method also yielded results which did not agree with the results obtained from the hydrostatic weighing procedure.

In conclusion, the results of the present study do not support the investigator's hypothesis that a combined training program will elicit more favorable changes in body composition than either method of training alone.

A number of factors could have contributed to the results which were obtained. These include:

1) The subject population size for each group was too small to reach statistical significance given the changes that could occur in 10-weeks.

2) Diet was not controlled during the 10-weeks of the study. Thus, an indication of each subject's average caloric intake was not known to allow comparison with his caloric expenditure. Outside physical activity was not controlled or monitored during the 10-week period.

3) After beginning the study, a limitation encountered was use of the dead-lift exercise in the weight training protocol. This exercise proved to be unpopular with the subjects as some experienced low-back strain or soreness during the pre-test and the initial two weeks of the 
study. A better exercise could have been either sit-ups, bicep curls or tricep extension. These exercises could have provided some muscle mass development and probably would have been met with much more acceptance by the subjects. 
IMPLICATIONS FOR FUTURE RESEARCH

The present study attempted to answer the question of how to elicit changes in body composition through various training methods. The main focus of the study looked at effects of a combined training program on body composition parameters as compared to either method of training alone. Although the results were not as expected, several points seem worthy of consideration for future research:

1. The concept of a combined training program for developing and/or maintaining fitness is still sensible for a number of physiological reasons. The use of weight training for increasing fat-free weight warrants further exploration as it can have an effect on metabolism and daily caloric expenditure. Also, the development of strength and muscle endurance can be facilitated. Endurance activities can produce alterations in cardiorespiratory fitness and absolute fat. Further, in terms of time-effectiveness a combined approach is best suited for meeting the time constraints of the average working individual. The present study used a traditional weight 
training program as part of the combined method and it proved difficult in meeting the time constraints of the study. Also, the traditional weight training program is limited in the number of muscle groups that can be exercised during a 20-minute period. It is recommended that a circuit weight training program be implemented in place of traditional weight training. Circuit weight training can utilize a greater number of muscle groups in a given period of time.

2. Future research should be directed at investigating a combined CWT program with an equal amount of endurance training. Gettman (13) investigated the effects of a supercircuit program on body composition but the endurance component was placed between each weight station. Repeated anaerobic intervals consisting of thirty 30-second running stations ( 15 minutes total time) were used in place of a continuous 15-minute endurance activity.

3. If an individual desires to develop lấrge amounts of strength and muscle hypertrophy then it is recommended that the weight training session be separate from the endurance session. Hickson (15) concluded in his study that individuals wishing to 
improve overall strength might find it detrimental to perform an endurance activity at the same time as weight training. In other words, by performing a combined weight training and endurance program at the same time, improvement in strength might be less than what could have been achieved if weight training had been performed alone.

Evaluating the effects of training programs on the components of body composition is usually done by comparing pre- and post-test relative fat scores. As indicated in the discussion in Chapter III and in Table I, hypothetical changes in relative fat can be altered by several factors. These include: loss of absolute fat, gain in fat-free weight, and a combined loss of absolute fat and gain in fat-free weight. If one wishes to evaluate completely a given training program, then net changes in body tissue should be taken into consideration. Such changes in body composition can be expressed by the ratio of the change in absolute fat ( $\triangle A F$ ) to the change in fat-free weight $(\triangle F F W)$. The direction of change is expressed by the sign that corresponds with the change in each tissue component. Thus, a minus sign (-) represents loss and a positive sign (t) represents a gain in that particular tissue component. Table XIII presents data comparing the present study and recalculated data from several of the studies cited in 


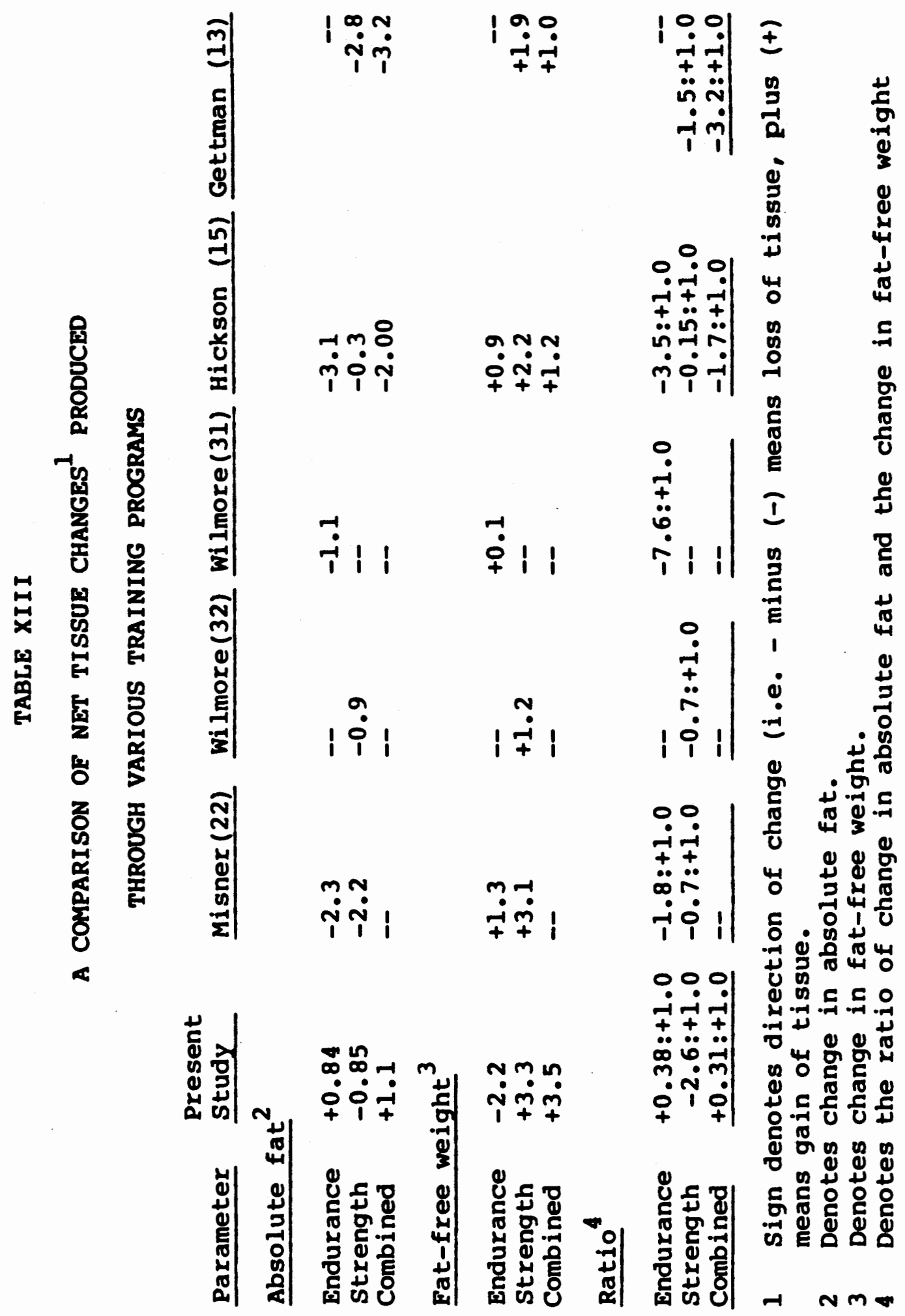


the review of literature. For purposes of comparison, all ratios are reported such that the changes in fat weight are expressed per unit change in fat-free weight. Data from the present study shows a ratio of $(+0.38:+1.0)$ for the endurance group, $(-2.6:+1.0)$ for the strength group and $(+0.31:+1.0)$ for the combined group. For reasons discussed earlier the ratios for both the endurance group and combined groups do not reflect changes that are consistent with previous data concerning alterations produced through endurance activities $(2,3,5,11,12,16,18,26,31)$. The studies of Misner (22), Wilmore $(31,32)$, Gettman (13) and Hickson (15) will be used to provide support for the hypothesis that the tissue change ratio ( $\triangle \mathrm{AF}: \triangle \mathrm{FFW}$ ) provides a useful method for evaluating changes in body composition.

Misner's (22) results produced ratios of $(-1.8:+1.0)$ for jogging and $(-0.7:+1.0)$ for weight training. Wilmore's data (32) on weight training produced a ratio of $(-0.7:+1.0)$ which coincides with Misner's data. In a separate study, wilmore (31) investigated endurance training and the results produced a ratio of $(-7.6:+1.0)$. Hickson's data (15) shows that a combined program $(-1.7$ : $+1.0)$ produced a more balanced tissue ratio than did either the strength training only $(-.15:+1.0)$ or endurance training only $(-3.5:+1.0)$ groups. Gettman's (13) data 
produced ratios for the combined supercircuit. program of $(-3.2:+1.0)$ and for the regular CWT program of $(-1.5$ : $+1.0)$.

As the above data suggest, there is great variability in net tissue change produced by various types of training and by various experimental designs. The tissue change ratio could be very useful in indicating the effectiveness of a given training program in producing changes in body composition. Some possible examples of variations in exercise prescription are examined below:

1. Endurance programs in most cases found a greater loss in absolute fat for every kilogram of fat-free weight gained $(15,22,31)$. This type of program would be recommended for individuals who have large amounts of absolute fat (i.e. moderate to severe obesity) and who need to reduce their relative fat levels to acceptable and manageable levels prior to any other treatment. The endurance program would in most cases consist of a walking protocol instead of jogging.

2. A weight lifting program might be suggested for an individual who already possessed a low to average level of absolute fat but who needed to increase strength and muscle mass (i.e. - wrestler, football player, shotputter, etc.). The need for 
developing strength would far outweigh the benefit of losing absolute fat as it probably would not be of concern to such an individual.

3. The data on combined programs is limited at present. It seems possible that a combined program might be recommended as a way to maintain a given level of body composition and fitness. In summary, methods for developing and maintaining a desirable body composition need further research. There is reason to believe that a combined training program can provide adequate training to develop and/or maintain stength and cardiorespiratory fitness in a time-efficient manner. Also, the concept of net tissue change should be further explored as a.method for evaluating the effectiveness of weight reduction programs on body composition. There still is great variability concerning actual changes produced through various training programs. If a reliable index of changes in body tissues could be developed and refined, then exercise prescription could become much more effective in meeting the needs of the general public and the competitive athlete. 


\section{LIST OF REFERENCES}

1. Allen, J. 1976. "Hemodynamic Consequences of Circuit Weight Training" Res. Quarterly 47:299-306.

2. American College of Sports Medicine, 1978. "The Recommended Quantity and Quality of Exercise for Developing and Maintaining Fitness in Heal thy Adults" Med. Sci. Sports 10(3): vii-x.

3. Boileau, R.A. 1971. "Body Composition Changes in Obese and Lean Men during Physical Conditioning" Med. Sci. Sports 3(4): 183-189.

4. Brozek, J. and A. Keys. 1963. "Densitometric Analysis of Body Composition: Revision of Some Quantitative Assumptions" Annals of N.Y. Acad. Sci. 110:113-140.

5. Clausen, Jan 1977. "Effects of Physical Training on Cardiovascular Adjustments to Exercise in Man" Phys. Reviews 57(4): 779-812.

6. CRC, 1983. Handbook of Chemistry and Physics, CRC Press, Inc., Boca Raton, Florida.

7. Durnin, J.V.C.A. and R. Passmore 1967. Energy, Work and Leisure, London: Heineman Educational Books, Ltd.

8. Gay, L.R. 1981. Educational Research: Competencies for Analysis and Application, Charles E. Merrill Publishing Co., Columbus, Ohio.

9. Gettman, Larry 1976. "Physiological Responses of Men to 1,3 and 5 days per week of Training Programs" Res. Quarterly 47: 638-646.

10. Gettman, Larry 1978. "The Effects of Circuit Weight Lifting on Strength, Cardiorespiratory Function and Body Composition" Med. Sci. Sports 10(3): $171-176$.

11. Gettman, Larry 1979. "Physiological Effects on Adult Men on Circuit Strength Training and Jogging" Arch. Phy. Rehab. Med. 60: 115-120.

12. Gettman, Larry 1981. "Circuit Weight Training: A Critical Review of Its Physiological Benefits" Phys. Sptmed. $9: 44-60$. 
13. Gettman, Larry , Paul Ward and R. Hagan. 1982. "A Comparison of Combined Running and Weight Training with Circuit Weight Training" Med. Sci. Sports $14(3): 229-234$.

14. Girandola, R., and V. Katch. 1973. "Effects of 9-weeks of Physical Training on Aerobic Capacity and Body Composition in College Males" Arch. Phy. Med. Rehab. $54: 521-24$.

15. Hickson, R.C. 1980. "Interference of Strength Development by Simultaneously Training for Strength and Endurance Training" Eur. J. Appl. Phys. 45, 255-263.

16. Holloszy, J.0., R. Hickson and J. Hagberg. 1980. "Physiological Consequences on the Biochemical Adaptations to Endurance Exercise" Annals of N.Y. Acad. Sci. 301:440-450.

17. Jackson, A. and M. Pollock. 1978. "Generalized Equations for Predicting Body Density for Men "Br. J. Nutr. 40:497-504.

18. Johnson, Glen. 1982. "Effects of a 16-week Marathon Training Program on Normal College Males" J.Sp. Med. Phy. Fit. 22(2): 224-229.

19. Karvonen, M.J., E. Kentala and O. Mustala. 1957. "The Effects of Training on Heart Rate" Annals Medic. Exper. et Biol. Fenniae 35:307-315.

20. Katch, F. and W. McArdle. 1977. Nutrition, Weight Control and Exercise, Houghton Miffin Co., Boston.

21. Katch, F. and V. Katch. 1980. "Muscular Development and Lean Body Weight in Body Builders and Weight Lifters" Med. Sci. Sports 12(5): 340-344.

22. Misner, J.E. 1974. "Alterations in Body Composition with Selected Physical Training Programs" J. AM. Geriat. Society 22:133-138.

23. Nagle, F. and I. Irwin. 1960. "Effects of Two Systems of Weight Training on Cardiorespiratory Endurance and Related Physiological Factors" Res. Quart. 31(4): $607-614$. 
24. Nie, N., C. Hull and D. Burt. 1975. Statistical Package for the Social Sciences, McGraw-Hill, Inc. New York.

25. Pollock, M., R. Bohannon, and K. Cooper. 1976. "A Comparative Analysis of Four Protocols for Maximal Treadmill Stress Testing" Am. Heart J. 92:39-46.

26. Saltin, B. and I. Rowell. 1980. "Functional Adaptations to Physical Activity and Inactivity" Fed. Proc. 39: 1506-1513.

27. Sharkey, Brian. 1979. Physiology of Fitness, Human Kinetic Publishers, Champaign, Illinois.

28. Siri, W.E. 1961. "Body Composition from Fluid Spaces and Density: Analysis of Methods." IN : Techniques for Measuring Body Composition, Nat. Acad. Sci.Nat. Research Council, Washington, D.C., pp. 223-24.

29. Thompson, J., G. Jarvie and B. Lahey. 1982. "Exercise and Obesity: Etiology, Physiology and Intervention" Psy. Bulletin 91(1): 55-79.

30. Wildt, A. and 0. Ahtola. 1978. Analysis of Covariance, Sage Publications, Beverly Hills.

31. Wilmore, J., R. Girandola and F. Katch. 1970. "Body Composition Changes with a 10-week Program of Jogging" Med. Sci. Sports 2(3): 113-117.

32. Wilmore, Jack. 1974. "Alterations in Strength, Body Composition and Anthropometric Measurements Consequent to a 10-week Weight Training Program" Med. Sci. Sports 6: 133-138.

33. Wilmore, J. 1977. Athletic Training and Physical Fitness, Allyn and Bacon, Inc., Boston.

34. Wilmore, J., P. Vodak and R. Parr. 1980. "Further Simplification of a Method for Determination of Residual Volume" Med. Sci. Sports 12(3): 216-218.

35. Yuhasz, M.S. 1965. "Physical Fitness and Sports Appraisal Laboratory Manual" University of Western ontario. 
APPENDICES 


\section{APPENDIX A}

\section{INTERVIEW QUESTIONNAIRE}

Are you presently involved in a weight lifting or running class? Y N Program? Y N

Are you available during MWF from 8:30 to 10:00 a.m.? Y N This study is planned to overlap into the spring term by 5 weeks and requires participation during the spring break, do you see any conflict regarding this matter? Y N

Is there a possible class involvement during the spring quarter that you might need to take? $\mathrm{Y} \quad \mathrm{N}$

Do you have any medical problems that might prevent $100 \%$ participation on your part? $\quad \mathrm{Y} \quad \mathrm{N}$ Are you presently on doctor prescribed medication? $\quad \mathrm{Y} \quad \mathrm{N}$ If yes, what kind?

Have you had surgery of any kind in the past 6 months? $Y \quad N$ If yes, what kind?

Have you been in the hospital in the past 6 months? $\mathrm{Y} N$ If yes, why? 
* Are you aware that you may be in the control group and be assigned to a no participation role in this study? Y N

Are you presently enrolled in an activity class? $\quad \mathrm{Y} N$ If yes, what?

Subsequent to recruiting subjects, it was decided in view of the small number of volunteers that a separate control group would be recruited and tested rather than randomly assigning some of the original volunteers into the control. 


\section{APPENDIX B}

\section{INFORMED CONSENT}

I, - hereby agree to serve as a subject in the research project titled "The Effects of a Combined Weight Training and Running Program on Body Composition in College Males" conducted by Robert L. Hesslink Jr. under the supervision of Dr. Milan Svoboda.

I understand that the study involves participation in body composition assessment, physical conditioning through weight training and/or running and there is a possibility that I may fall into the control group which will remain inactive during the course of the study. I understand that possible risks to me associated with this study are muscular fatigue, muscle soreness, and muscle strain. I also understand that participation in this study requires my involvement for 16 weeks on Monday-Wednesday-Friday from 8:30 to 10:00 a.m. including spring break.

It has been explained to me that the purpose of the study is to learn possible alternative methods for the 
maintenance and/or development of body composition. I may not receive any direct benefit from participation in this study but my participation may help to increase knowledge which may benefit others in the future. Robert L. Hesslink $\mathrm{Jr}$. has offered to answer any questions I may have about the study and any related material. I have been assured that all information I give will be kept confidential and that the identity of all subjects will remain anonymous.

I understand that I am free to withdraw from participation in this study at any time without jeopardizing my relationship with portland State University.

I have read and understand the foregoing information. Date Signature

If you experience problems that are the result of your participation in this study, please contact Dr. John Lorentz, office of Graduate Studies and Research, 105 Neuberger Hall, Portland State University, 229-3423. 